This Section of Epidemiology and Psychiatric Sciences appears in each issue of the Journal to stress the role of the epidemiological approach to promote advances in the field of clinical psychopharmacology, with a particular attention to controversial findings. The ultimate aims are to help develop a more critical attitude towards the results of research studies published in the international literature, to promote original research projects with higher methodological standards, and to implement the most relevant results of research in every-day clinical practice. These contributions are written in house by the journal's editorial team or commissioned by the Section Editor (no more than 1000 words, short unstructured abstract, 4 key-words, one Table or Figure and up to ten references).

\title{
Adherence to generic $v$. brand antidepressant treatment and the key role of health system factors
}

\author{
C. Barbui ${ }^{1 *}$ and V. Conti ${ }^{2}$ \\ ${ }^{1}$ Department of Public Health and Community Medicine, Section of Psychiatry, University of Verona, Verona, Italy \\ ${ }^{2}$ Regional Centre for Pharmacovigilance, Lombardy Region, Milan, Italy
}

\begin{abstract}
One of the major challenges with antidepressant (AD) use is poor adherence and early treatment discontinuation. In addition to socio-demographic and clinical variables, treatment discontinuation may also be related to the capacity of the health system to assure and maintain continuity and intensity of care. Among health system factors that may interfere with adherence to pharmacological treatment, use of generic drugs may play a key role. It has been argued that, although the lower cost of generics may favour persistence on treatment, a widespread a priori scepticism about their effectiveness and safety by doctors and patients may have an opposite effect. This compelling research question has recently been addressed by an observational cohort study that involved 16778 Medicare fee-for-service beneficiaries who received a new depression diagnosis and initiated generic $v$. brand AD therapy. The study found that generic initiation was associated with improved adherence. The benefits resulted from the lower out-of-pocket cost associated with generic ADs. In this commentary, we discuss the main findings of this study in view of its methodological strengths and limitations, and we suggest implications for policy.
\end{abstract}

Received 19 October 2014; Revised 17 November 2014; Accepted 17 November 2014; First published online 18 December 2014

Key words: Adherence, antidepressant, health system, policy.

Antidepressants (ADs) are one of the most prescribed drug classes, with a reported increasing trend in use (McCarthy, 2013). In the USA, for example, the overall prevalence of use increased from $6.5 \%$ in 1999-2000 to $10.4 \%$ in 2009-2010 (Mojtabai \& Olfson, 2014). In Europe, a recent overview of $\mathrm{AD}$ prescribing in seven different databases from five European countries showed the highest prevalence of prescribing in the UK and the lowest in the Netherlands, with Spain, Denmark and Germany in between (Abbing-

* Address for correspondence: Professor C. Barbui, Department of Public Health and Community Medicine, Section of Psychiatry, University of Verona, Piazzale L.A. Scuro, 10 - 37134 Verona, Italy.

(Email: corrado.barbui@univr.it)
Karahagopian et al. 2014). In Italy, AD use increased from 27.5 to $39.1 \%$ defined daily doses per 1000 inhabitants/day in the period 2005-2013 (OSMED, 2014).

One of the major challenges with $\mathrm{AD}$ use is poor adherence and early treatment discontinuation, which may have negative consequences in terms of treatment effectiveness and patient outcomes. Adherence can be as low as $20-30 \%$ over the treatment period, ranging from 6 months to several years (Vlahiotis et al. 2011). In a recent study carried out in Italy, more than $70 \%$ of the population of patients with severe mental disorders discontinued AD treatment over 12 months after initial prescription (and almost $60 \%$ over 6 months; Conti et al. 2012). Socio-demographic variables, clinical features of 
depression, comorbidities, pharmacological factors, attitude towards ADs, previous experiences of $\mathrm{AD}$ treatment, patient-professional relationship and genes were found to be factors associated with poor adherence (Hung, 2014).

However, treatment discontinuation may also be a factor related to the capacity of the health system to assure and maintain continuity and intensity of care. Among health system factors that may interfere with adherence to pharmacological treatment, use of originator (brand-name) drugs, strongly supported by healthcare systems which recommend physicians to prefer them rather than brand-name drugs, may play a key role. It has been argued that, although the lower cost of generics may favour persistence on treatment (Shrank et al. 2006), a widespread a priori scepticism about their effectiveness and safety by doctors and patients may have an opposite effect (Himmel et al. 2005). A recent study by Bao et al., who conducted a longitudinal survey of an epidemiologically representative sample of Medicare fee-for-service beneficiaries in the USA, expended current knowledge on this compelling issue (Bao et al. 2013).

In the USA, generic use might be associated with increased adherence because patient out-of-pocket costs for generics are nearly always much lower than they are for brands. Choice of generic or brand name is partly a function of provider preferences, and when a branded drug is prescribed in absence of a 'dispense as written' request by the prescriber or the patient, patients often receive a generic equivalent because of state mandates of generic substitution (Bao et al. 2013). Bao et al. enrolled a 5\% random sample of Medicare fee-for-service beneficiaries who received a new depression diagnosis in the first half of 2007 and initiated generic or brand AD therapy within 60 days $(n=16778)$. Adherence to AD therapy was measured by (a lack of) disruption in medication use defined by a gap of 30 days or more in AD possession and monthly days of possession, both measured over 180 days since the AD initiation. More than half of participants received a low-income subsidy (LIS) which means that they were not subject to any out-of-pocket expenditure. Therefore, in this subgroup, the impact of generic $v$. brand AD prescribing was expected to be lower as compared with those who were not eligible for an LIS (Bao et al. 2013).

The study found that generic AD initiation was associated with improved adherence, with a stronger effect among the non-LIS patients. Among the LIS patients, the rate of AD disruption ranged from 29 to $31 \%$ in aged and disabled patients, whereas among the non-LIS patients, the rates were significantly higher, ranging from 35 to $39 \%$ in aged and disabled patients. Cox model showed that generic initiation was associated with a lower hazard of $\mathrm{AD}$ treatment disruption across all four subgroups. The authors concluded that, in this system of health care, initiating the therapy with a generic AD was consistently associated with increased medication adherence. The benefits resulted from the lower out-of-pocket cost associated with generic ADs. This finding is in line with the current evidence linking out-of-pocket cost differentials between generic and branded medications to substantially increased adherence among patients starting with a generic medication for several chronic medical conditions. Another interesting finding was that, around half of the disruption in AD therapy occurred during 30 days after initiation (early discontinuation; Bao et al. 2013).

As with all studies that use claims data, there are limitations that should be recognised. First, the study was unable to adjust for clinical variables that may influence the choice of branded $v$. generic $\mathrm{AD}$. It might be a hypothesis, for example, that patients who were prescribed a brand AD were at higher risk of treatment non-adherence, as doctors might have been reluctant to prescribe generics to patients whom they perceived as having a high risk of non-adherence. Second, the lack of data on whether patients eventually took the prescribed agents should be highlighted, since a relevant proportion of the medicines prescribed for people with chronic conditions are not taken (Jones, 2003). Additionally, AD dose, combinations of different $\mathrm{AD}$ agents and switches have not been taken into consideration. Finally, according to the definition of discontinuation, during the last 30 days of the 180 days of follow-up, patients could not discontinue $\mathrm{AD}$ therapy. The consequences of this short window (30 days) of 'immortal-time' (Rothman et al. 2008) are expected to be the following: (i) the disruption rate among groups (29, 31, 35 and 39\%) may be slightly underestimated; (ii) the association estimated by the Cox model might be stronger, thus suggesting an even greater impact of the results originally reported by the authors.

Strengths of this study include adjustment for confounders that should always be considered in persistence analyses: age, sex, race/ethnicity, an indicator of comorbidity status and prescriber status (primary care doctor, mental health/other medical specialty).

In terms of implications for policy, a reason for concern is whether these findings may apply to healthcare systems which have implemented drug policies that are radically different as compared with this Medicare fee-for-service scheme (Corrao et al. 2014). It may be argued, however, that what may be generalised is the finding that lower out-of-pocket costs are associated with increased adherence. Prescribing generics, which are associated with lower costs in most 
healthcare systems, may therefore be considered as a tool for increasing adherence to AD treatment. What still remains to be investigated is whether this beneficial effect might be counterbalanced by potential concerns of doctors and patients on the effectiveness and safety of generic drugs. The quality of generics might be another concern in countries that do not have strict regulations similar to the Food and Drug Administration in the USA and European Medicine Agency in Europe. As these concerns are expected to be widely heterogeneous and heavily connected with local variables and cultures, the need for more epidemiological studies linking clinically relevant variables, such as treatment adherence, with drug policy and healthcare system factors, should be strongly emphasised (Minas \& Cohen, 2007; Eaton, 2008).

Indirectly, these findings would also suggest that, in countries where there is a little or no co-pay for drugs, increased use of generics $v$. originators as well as $v$. patented products can save considerable resources (Godman et al. 2014). Therefore, the implementation of measures aimed at increasing the prescribing of generics, such as for example high voluntary International Non-proprietary Name prescribing rates in the UK, compulsory generic substitution in Sweden as well as switching targets among pharmacists in France, should be considered by health systems both as a costcontainment strategy, and as a clinically reasonable strategy to increase treatment adherence (Abuelkhair et al. 2012).

We need to know how to plan and organise services and improve the use of scarce financial and human resources in order to provide effective treatments to those who need care (Saraceno, 2007), including pharmacological treatments. More generally, we need to expand current knowledge and experience on all those system factors that may play a crucial role in improving access to, and rational use of, psychotropic medicines.

\section{Financial Support}

No financial support was received for this paper from any funding agency, commercial or not-for-profit sectors

\section{Conflict of Interest}

None.

\section{References}

Abbing-Karahagopian V, Huerta C, Souverein PC, de Abajo F, Leufkens HG, Slattery J, Alvarez Y, Miret M, Gil M, Oliva
B, Hesse U, Requena G, de Vries F, Rottenkolber M, Schmiedl S, Reynolds R, Schlienger RG, de Groot MC, Klungel OH, van Staa TP, van Dijk L, Egberts AC, Gardarsdottir H, De Bruin ML (2014). Antidepressant prescribing in five European countries: application of common definitions to assess the prevalence, clinical observations, and methodological implications. European Journal of Clinical Pharmacology 70, 849-857.

Abuelkhair M, Abdu S, Godman B, Fahmy S, Malmstrom RE, Gustafsson LL (2012). Imperative to consider multiple initiatives to maximize prescribing efficiency from generic availability: case history from Abu Dhabi. Expert Review of Pharmacoeconomics and Outcomes Research 12, 115-124.

Bao Y, Ryan AM, Shao H, Pincus HA, Donohue JM (2013). Generic initiation and antidepressant therapy adherence under medicare part D. American Journal of Managed Care 19, 989-998.

Conti V, Lora A, Cipriani A, Fortino I, Merlino L, Barbui C (2012). Persistence with pharmacological treatment in the specialist mental healthcare of patients with severe mental disorders. European Journal of Clinical Pharmacology 68, 1647-1655.

Corrao G, Soranna D, La Vecchia C, Catapano A, Gabiti-Rosei E, Gensini G, Merlino L, Mancia G (2014). Medication persistence and the use of generic and brand-name blood pressure-lowering agents. Journal of Hypertension 32, 1146-1153.

Eaton J (2008). Ensuring access to psychotropic medication in sub-Saharan Africa. African Journal of Psychiatry 11, 179-181.

Godman B, Wettermark B, Fraeyman J, Varez-Madrazo S, Berg C, Bishop I, Bucsics A, Campbell S, Finlayson AE, Furst J, Garuoliene K, Herholz H, Kalaba M, Laius O, Piessnegger J, Sermet C, Schwabe U, Vlahovic-Palcevski VV, Markovic-Pekovic V, Voncina L, Malinowska K, Zara C, Gustafsson LL (2014). Multiple policies to enhance prescribing efficiency for established medicines in Europe with a particular focus on demand-side measures: findings and future implications. Frontiers in Pharmacology 5, 106.

Himmel W, Simmenroth-Nayda A, Niebling W, Ledig T, Jansen RD, Kochen MM, Gleiter CH, Hummers-Pradier E (2005). What do primary care patients think about generic drugs? International Journal of Clinical Pharmacology and Therapeutics 43, 472-479.

Hung CI (2014). Factors predicting adherence to antidepressant treatment. Current Opinion in Psychiatry 27, 344-349.

Jones G (2003). Prescribing and taking medicines. BMJ $327,819$.

McCarthy M (2013). Antidepressant use has doubled in rich nations in past 10 years. BMJ 347, f7261.

Minas H, Cohen A (2007). Why focus on mental health systems? International Journal of Mental Health Systems 1, 1.

Mojtabai R, Olfson M (2014). National trends in long-term use of antidepressant medications: results from the U.S. National Health and Nutrition Examination Survey. Journal of Clinical Psychiatry 75, 169-177.

OSMED (2014). L'uso dei farmaci in Italia. Osservatorio nazionale sull'impiego dei medicinali: Rome. 
Rothman K, Greenland S, Lash T (2008). Modern Epidemiology, 3rd edn. Lippincott, Williams \& Wilkins: Philadelphia, PA.

Saraceno B (2007). Mental health systems research is urgently needed. International Journal of Mental Health System 1, 2.

Shrank WH, Hoang T, Ettner SL, Glassman PA, Nair K, DeLapp D, Dirstine J, Avorn J, Asch SM (2006). The implications of choice: prescribing generic or preferred pharmaceuticals improves medication adherence for chronic conditions. Archives of Internal Medicine 166, 332-337.

Vlahiotis A, Devine ST, Eichholz J, Kautzner A (2011). Discontinuation rates and health care costs in adult patients starting generic versus brand SSRI or SNRI antidepressants in commercial health plans. Journal of Managed Care Pharmacy 17, 123-132. 